\title{
Silymarin Component 2,3-dehydrosilybin Attenuates Cardiomyocyte Damage Following Hypoxia/Reoxygenation by Limiting Oxidative Stress
}

\author{
E. GABRIELOVÁ ${ }^{1,2}$, V. KŘEN ${ }^{3}$, M. JABŮREK ${ }^{4}$, M. MODRIANSKÝ ${ }^{1}$
}

${ }^{1}$ Department of Medical Chemistry and Biochemistry, Faculty of Medicine and Dentistry, Palacky University, Olomouc, Czech Republic, ${ }^{2}$ Institute of Molecular and Translational Medicine, Faculty of Medicine and Dentistry, Palacky University, Olomouc, Czech Republic, ${ }^{3}$ Institute of Microbiology, Academy of Sciences of the Czech Republic, Prague, Czech Republic, ${ }^{4}$ Institute of Physiology, Academy of Sciences of the Czech Republic, Prague, Czech Republic

Received November 11, 2013

Accepted June 5, 2014

On-line September 5, 2014

\section{Summary}

Ischemic postconditioning and remote conditioning are potentially useful tools for protecting ischemic myocardium. This study tested the hypothesis that 2,3-dehydrosilybin (DHS), a flavonolignan component of Silybum marianum, could attenuate cardiomyocyte damage following hypoxia/ reoxygenation by decreasing the generation of reactive oxygen species (ROS). After 5-6 days of cell culture in normoxic conditions the rat neonatal cardiomyocytes were divided into four groups. Control group ( $9 \mathrm{~h}$ at normoxic conditions), hypoxia/ reoxygenation group $\left(3 \mathrm{~h}\right.$ at $1 \% \mathrm{O}_{2}, 94 \% \mathrm{~N}_{2}$ and $5 \% \mathrm{CO}_{2}$ followed by $10 \mathrm{~min}$ of $10 \mu \mathrm{mol} \cdot \mathrm{l}^{-1} \mathrm{DHS}$ and $6 \mathrm{~h}$ of reoxygenation in normoxia) and postconditioning group ( $3 \mathrm{~h}$ of hypoxia, three cycles of 5 min reoxygenation and 5 min hypoxia followed by $6 \mathrm{~h}$ of normoxia). Cell viability assessed by propidium iodide staining was decreased after DHS treatment consistent with increased levels of lactatedehydrogenase (LDH) after reoxygenation. $\mathrm{LDH}$ leakage was significantly reduced when cardiomyocytes in the $\mathrm{H} / \mathrm{Re}$ group were exposed to DHS. DHS treatment reduced $\mathrm{H}_{2} \mathrm{O}_{2}$ production and also decreased the generation of ROS in the $\mathrm{H} / \mathrm{Re}$ group as evidenced by a fluorescence indicator. DHS treatment reduces reoxygenation-induced injury in cardiomyocytes by attenuation of ROS generation, $\mathrm{H}_{2} \mathrm{O}_{2}$ and protein carbonyls levels. In addition, we found that both the postconditioning protocol and the DHS treatment are associated with restored ratio of phosphorylated/total protein kinase $C$ epsilon, relative to the $\mathrm{H} / \mathrm{Re}$ group. In conclusion, our data support the protective role of DHS in hypoxia/reperfusion injury and indicate that DHS may act as a postconditioning mimic.

\section{Key words}

Silymarin • Dehydrosilybin • Neonatal rat cardiomyocytes • Postconditioning • Reactive oxygen species

\section{Corresponding author}

M. Modrianský, Department of Medical Chemistry and Biochemistry, Faculty of Medicine and Dentistry, Palacky University, Hněvotínská 3, 77515 Olomouc, Czech Republic. E-mail: oregon@tunw.upol.cz

\section{Introduction}

Silymarin, a seed extract from milk thistle plant Silybum marianum, has been used to treat a range of liver and gallbladder disorders, including hepatitis and cirrhosis, and to protect the liver against poisonings from chemical and environmental toxins (Rambaldi et al. 2005). The effects of silymarin, including its effect on cell signaling pathways, its pharmacokinetics, pharmacodynamics, tissue distribution, bioavailability and safety in humans, summarized by Agarwal et al. (2006) and others (Kren et al. 2013). Other studies have demonstrated that silymarin has cardioprotective activity in ischemia-reperfusion-induced myocardial infarction 
(Rao and Viswanath 2007) and oxidative stress in mice and rat cardiac tissues (Nabavi et al. 2012, Taghiabadi et al. 2012).

The silymarin mixture contains several major (Ding et al. 2001) as well as minor polyphenolic compounds (Kim et al. 2003). The flavonolignans silybin, isosilybin, silychristin, silydianin, 2,3-dehydrosilybin (DHS), flavonoid taxifolin and polymeric polyphenolic compounds are the main active compounds that have interesting and important therapeutic activities. Silybin (SB) represents more than $50 \%$ of the silymarin mixture and is generally thought to be the most therapeutically active component (Comelli et al. 2007). However, it was suggested that not the major flavonolignans, but the minor components are responsible for the antioxidant capacity of the silymarin mixture (Kvasnicka et al. 2003, Gabrielova et al. 2010, Weidmann 2012).

Ischemia/reperfusion $(\mathrm{I} / \mathrm{R})$ injury is characterized by significant oxidative stress, which induces characteristic changes in the antioxidant system and organ injury leading to significant morbidity and mortality. Cardiomyocytes can resist ischemia/ reperfusion injury through ischemic postconditioning, i.e. a repetitive ischemia induced during the onset of reperfusion (Zhao et al. 2003, Vinten-Johansen 2007, Hausenloy and Yellon 2008). Ischemic postconditioning and remote conditioning are considered beneficial based on small clinical trials (Thibault et al. 2008, Garcia et al. 2010, Lonborg et al. 2010). Postconditioning was shown to reduce hypoxia/reoxygenation-induced cardiomyocyte necrosis and apoptosis (Sun et al. 2005, Wang et al. 2006).

Generation of reactive oxygen species (ROS) is a well established cause of heart injury induced by ischemia/reperfusion (Vanden Hoek et al. 1997, Becker et al. 1999). Mitochondria-generated superoxide anion and subsequently other ROS, such as hydrogen peroxide and hydroxyl radical, can compromise cell viability because of damage to proteins, lipids and nucleic acids. Under physiological conditions, cellular damage is diminished by antioxidant defences that neutralize ROS (Cadenas 1989). It was suggested that depending on their structures and concentrations antioxidants are able to protect against cardiovascular diseases (Guaiquil et al. 2004), and interest in the use of natural and synthetic antioxidants as functional food ingredients or as food supplements increases (Celik and Arinc 2010, Puertollano et al. 2011).
Recent research has pointed to receptors, kinase signaling pathways and mitochondrial participation in ischemic conditioning (Garlid et al. 2009, Buchholz et al. 2014). Pharmacological postconditioning represents administration of pharmacological agents at the time of reperfusion after a prolonged period of ischemia (Zhao et al. 2003, Zhao 2010) and modifications of the cardioprotective cell signaling pathways by pharmacological agents mimics the cardioprotection by ischemic postconditioning (Buchholz et al. 2014). Several pharmacological agents possess the ability of mimicking the effects of ischemic conditioning and can also reduce the number of cells dying during ischemia/reperfusion (Wang et al. 2011, Ye et al. 2011). Recent studies have shown that pools of various kinases, including Akt and protein kinase $\mathrm{C}$ epsilon (PKCE), are localized to mitochondria and play a critical role in cardioprotection (Garlid et al. 2009, Miura et al. 2010).

In the present study, we tested the hypothesis that DHS could attenuate cardiomyocyte damage following hypoxia/reoxygenation by decreasing the generation of ROS. Using rat neonatal cardiomyocytes, we observed a significant decrease of hypoxia/ reoxygenation injury in cardiomyocytes treated with a single dose of DHS. In addition, we found that both the postconditioning protocol and the administration of DHS are associated with restored ratio of phosphorylated/total PKC $\varepsilon$. In conclusion, our data support the protective role of DHS in hypoxia/reperfusion injury and indicate that DHS may act as a postconditioning mimic.

\section{Methods}

\section{Chemicals and test compounds}

Dulbecco's modified Eagle's medium (DMEM), heat-inactivated fetal bovine serum (FBS), stabilized penicillin-streptomycin solution (PenStrep), sterile dimethylsulfoxide (DMSO), propidium iodide (PI), horseradish peroxidase (HRP), $\beta$-nicotinamide adenine dinucleotide reduced disodium salt hydrate (NADH) and all other chemicals were obtained from Sigma-Aldrich (Prague, Czech Republic). Dihydrorhodamine 123 (DHR) was from Sigma-Aldrich (Prague, Czech Republic). Amplex red was from Life Technologies (Prague, Czech Republic).

2,3-dehydrosilybin (DHS, $98 \% ; \quad \mathrm{C}_{25} \mathrm{H}_{20} \mathrm{O}_{10}$, $\mathrm{Mr} 480$ ) was prepared at the Institute of Microbiology, Academy of Science of the Czech Republic, Prague, Czech Republic. The method of DHS preparation is based 
on base-catalyzed disproportionation (Gažák et al. 2013). Silybin (2.5 g, $5.183 \mathrm{mmol})$ and $\mathrm{NaHCO}_{3} \quad(1.74 \mathrm{~g}$, $20.798 \mathrm{mmol})$ were dissolved in methanol $(100 \mathrm{ml})$ and the mixture was heated under reflux for $16 \mathrm{~h}$. The mixture was then left to cool to room temperature and poured into ice-cold water containing $\mathrm{HCl}(400 \mathrm{ml}, 5 \% \mathrm{v} / \mathrm{v})$. The precipitate formed was filtered off, washed with $\mathrm{H}_{2} \mathrm{O}$, dissolved in a mixture of ethyl acetate/acetone (1:1), and evaporated to give $2.17 \mathrm{~g}$ of dry residue. The solid was crystallized from methanol (1000 mg, $40 \%$ yield). The mother liquor was filtered through a silica gel pad ( $\mathrm{CHCl}_{3}$ /acetone/HCOOH $\left.90: 10: 1-70: 30: 1\right)$ to obtain, after concentration, another portion of the product, which after recrystallization from methanol yielded pure DHS (270 mg, $11 \%$ ). Thus, the total yield of DHS was $51 \%$. Stock solution of DHS $\left(10 \mathrm{mmol} \cdot l^{-1}\right)$ was prepared in DMSO. The final concentration of DMSO in the medium was $0.5 \%(\mathrm{v} / \mathrm{v})$.

\section{Animals}

Wistar rats (250 to $275 \mathrm{~g}$ ) were bred and housed in a certified animal house according to EU rules and according to the Faculty of Medicine and Dentistry, Palacky University, in accordance with the Guide for the Care and Use of Laboratory Animals (1985), NIH, Bethesda, or European Guidelines on Laboratory Animal Care. Animal treatment and sacrifice procedure for neonatal rats was approved by the Ethical Committee for Laboratory Animal Treatment of the Faculty of Medicine and Dentistry, Palacky University.

\section{Isolation of neonatal rat cardiomyocytes}

The procedure described by Chlopcikova et al. (2001) was followed. Entire hearts were isolated from 2-5 day old rats and minced in a balanced salt solution containing in $\mathrm{mmol} \cdot \mathrm{l}^{-1}$ : $20 \mathrm{HEPES}, 120 \mathrm{NaCl}$, $1 \mathrm{NaH}_{2} \mathrm{PO}_{4}, \quad 5.5$ glucose, $\quad 5.4 \mathrm{KCl}$ and $0.8 \mathrm{MgSO}_{4}$ ( $\mathrm{pH}$ 7.3-7.4). The consequent trypsin digestion released cells that were resuspended in a medium containing Dulbecco's Modified Eagle Medium (DMEM) and a medium $199(4: 1)$ supplemented with horse serum $(10 \%)$, fetal calf serum $(5 \%)$, penicillin $\left(100 \mathrm{U} \cdot \mathrm{ml}^{-1}\right)$ and streptomycin $\left(100 \mu \mathrm{g} \cdot \mathrm{ml}^{-1}\right)$. The suspension enriched in non-adhesive myocytes was transferred to collagen I-coated culture dishes at a density of $5 \times 10^{4}$ cells per $\mathrm{cm}^{2}$. The cells were incubated in $95 \%$ air and $5 \% \mathrm{CO}_{2}$ at $37{ }^{\circ} \mathrm{C}$. The medium was removed after $72 \mathrm{~h}$ and replaced with a culture medium containing DMEM and medium $199(4: 1)$ with penicillin $\left(100 \mathrm{U} \cdot \mathrm{ml}^{-1}\right)$ and streptomycin $\left(100 \mu \mathrm{g} \cdot \mathrm{ml}^{-1}\right)$. Cultured cardiomyocytes were allowed to reach a confluence before being used experimentally. The percentage of beating myocardial cells exceeded $85-90 \%$ after 3 days in culture for each experiment.

We used commercial real-time xCELLigence RTCA system based on impedance measurement on microtiter plates that are integrated with gold microelectrodes (Ke et al. 2011), to determine the best cellular density conditions for our model. We monitored the viability profile of rat neonatal cardiomyocytes in real-time, thereby determining the optimal time for starting the hypoxia/reoxygenation experiments. Based on the data we subjected the cell culture to the hypoxia/reoxygenation treatment protocol within the time frame of $72-120 \mathrm{~h}$ after isolation and seeding (data not shown).

\section{Hypoxia/reoxygenation treatment protocol}

We used in vitro protocol for the cell culture model of hypoxia postconditioning according to an established procedure (Sun et al. 2005, 2006, Tu et al. 2012, Tang et al. 2014). After 5-6 days of cell culture in normoxic $10 \%$ FBS-DMEM, the culture medium was freshly changed with $1 \%$ FBS-DMEM, and the cardiomyocytes were divided into three groups as follows: 1. control (ctrl), in which cardiomyocytes were incubated for $9 \mathrm{~h}$ at normoxic conditions (Fig. 1A); 2. hypoxia/reoxygenation $(\mathrm{H} / \mathrm{Re})$, in which the culture dishes were transferred to a hypoxic incubator, atmosphere of $1 \% \mathrm{O}_{2}, 94 \% \mathrm{~N}_{2}$ and $5 \% \mathrm{CO}_{2}$ for $3 \mathrm{~h}$ followed by $6 \mathrm{~h}$ of reoxygenation (Fig. 1B); 3. postconditioning (PostC), in which cardiomyocytes were postconditioned after the $3 \mathrm{~h}$ index hypoxia by three cycles of $5 \mathrm{~min}$ of reoxygenation and $5 \mathrm{~min}$ of rehypoxia. After the three cycles of postconditioning $6 \mathrm{~h}$ of continuous normoxia was followed (Fig. 1C); 4. hypoxia/reoxygenation $(\mathrm{H} / \mathrm{Re})+\mathrm{DHS}$, in which the culture dishes were transferred to a hypoxic incubator, atmosphere of $1 \% \mathrm{O}_{2}, 94 \% \mathrm{~N}_{2}$ and $5 \% \mathrm{CO}_{2}$ for $3 \mathrm{~h}$ followed by $10 \mathrm{~min}$ of $10 \mu \mathrm{mol} \cdot \mathrm{l}^{-1}$ 2,3-dehydrosilybin and $6 \mathrm{~h}$ of reoxygenation (Fig. 1D). The incubator utilized for hypoxia experiments is equipped with $\mathrm{O}_{2}$ (Envitec OOM202-2) and $\mathrm{CO}_{2}$ (infrared diode) sensors allowing continuous monitoring of gas composition (Mezentech, Czech Republic). It maintains optimal temperature and variable gas concentration for in vitro cultivation of cells in various types of cultivation vessels (software Machine Code for AT-MEGA microprocessor). 
A

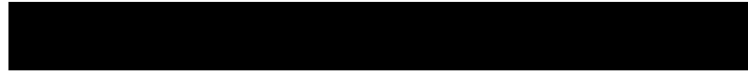

$9 \mathrm{~h}$ normoxia

B

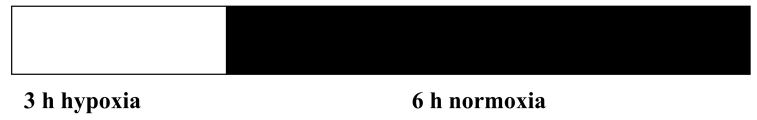

C

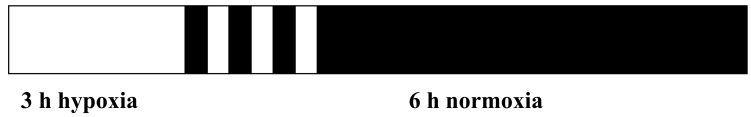

D

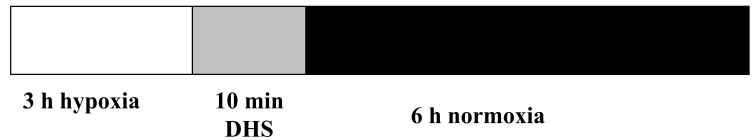

Fig. 1. Hypoxia/reoxygenation treatment protocol. Isolated rat cardiomyocytes were divided into four groups. A. control group (ctrl), in which cardiomyocytes were incubated for $9 \mathrm{~h}$ at normoxic conditions; B. hypoxia/reoxygenation $(\mathrm{H} / \mathrm{Re})$, in which the culture dishes were transferred to a hypoxic incubator, atmosphere of $1 \% \mathrm{O}_{2}, 94 \% \mathrm{~N}_{2}$ and $5 \% \mathrm{CO}_{2}$ for $3 \mathrm{~h}$ followed by $6 \mathrm{~h}$ of reoxygenation; C. postconditioning (PostC), in which cardiomyocytes were postconditioned after the $3 \mathrm{~h}$ index hypoxia by three cycles of 5 min of reoxygenation and $5 \mathrm{~min}$ of hypoxia. After the three cycles of postconditioning, $6 \mathrm{~h}$ of continuous normoxia was followed. D. hypoxia/reoxygenation with 2,3-dehydrosilybin (DHS), in which the culture dishes were transferred to a hypoxic incubator, atmosphere of $1 \% \mathrm{O}_{2}, 94 \%$ $\mathrm{N}_{2}$ and $5 \% \mathrm{CO}_{2}$ for $3 \mathrm{~h}$ followed by $10 \mathrm{~min}$ of $10 \mu \mathrm{mol}^{-1} \mathrm{I}^{-1} \mathrm{DHS}$ and $6 \mathrm{~h}$ of reoxygenation.

Identification and quantification of cell death by flow cytometry

Harvested cardiomyocytes were stained for $30 \mathrm{~min}$ in the dark with $1 \mathrm{ml}$ of Vindal's solution that consisted of $20 \mu \mathrm{g} \cdot \mathrm{ml}^{-1}$ RNase $\mathrm{A}, 20 \mu \mathrm{g} \cdot \mathrm{ml}^{-1}$ propidium iodide (PI) in the presence of $0.1 \%$ Triton X-100 to quantify total cell death. $0.5 \mathrm{ml}$ of the stained cardiomyocytes were mixed with $0.5 \mathrm{ml}$ of Vindal's solution and were analyzed by flow cytometry on Cytomics FC 500 (Beckman Coulter, Fullerton, CA, USA) as described (Vrba et al. 2009), counting 10,000 events per sample. The percentage of cells in sub-G1 peak was calculated using MultiCycle AV Software (Phoenix Flow Systems, San Diego, CA, USA) which eliminated the debris effect. Each experiment was performed in triplicate and independently repeated at least four times.

\section{Lactate dehydrogenase release assay}

The activity of lactate dehydrogenase (LDH) released into the culture medium via cell membrane disruption was measured spectrophotometrically. The method is based on LDH-catalysed reduction of pyruvate to lactate by an equimolar amount of NADH (Warburg optical test), the decrease of which was monitored at $340 \mathrm{~nm}$ (Warburg et al. 1935). After incubation, serumfree medium $(50 \mu \mathrm{l})$ was mixed with $150 \mu \mathrm{l}$ of fresh LDH buffer $\left(50 \mathrm{mmol} \cdot \mathrm{l}^{-1} \quad \mathrm{Na}_{2} \mathrm{HPO}_{4} ; 1.22 \mathrm{mmol} \cdot \mathrm{l}^{-1}\right.$ sodium pyruvate; $\mathrm{pH} 7.5)$ containing $\mathrm{NADH}\left(0.465 \mathrm{mmol}^{-1}\right)$ on a microplate and absorbance change over time $(\Delta \mathrm{A} / \mathrm{min})$ was monitored (Tecan Infinite M200, Tecan, Austria). The viability of treated cells was expressed in nkat $\cdot 1^{-1}$. Protein concentration was estimated using the Coommassie Blue method (Bradford 1976). Each experiment was performed in triplicate and independently repeated at least six times.

\section{Measurement of cellular oxidative stress}

The dihydrorhodamine 123 fluorescent probe (DHR, Molecular Probes) is converted into the fluorescent product rhodamine 123 by an interaction with $\mathrm{H}_{2} \mathrm{O}_{2}$ in the presence of peroxidase, cytochrome $\mathrm{c}$ or $\mathrm{Fe}^{2+}$ (Wardman 2007) and reacts also with peroxynitrite (Wardman 2008), making it a useful indicator of cellular oxidative stress. The fluorescence was monitored at specific excitation/emission wavelengths 488/525 nm. Cells were incubated with DHR $\left(5 \mathrm{nmol} \cdot 1^{-1}\right)$ for $15 \mathrm{~min}$ in the dark, then washed once with PBS, scraped into PBS and sonicated to release the formed rhodamine 123. After centrifugation $\left(2,000 \times \mathrm{g}, 10 \mathrm{~min}, 4^{\circ} \mathrm{C}\right)$, the fluorescence in the supernatant was measured using a microplate reader (Tecan Infinite M200, Tecan, Austria). Protein concentration was estimated using the Coommassie Blue method (Bradford 1976). The results were expressed as fluorescence of DHR per milligram of proteins. Each experiment was performed in triplicate and independently repeated at least six times.

\section{Measurement of $\mathrm{H}_{2} \mathrm{O}_{2}$ production}

The $\mathrm{H}_{2} \mathrm{O}_{2}$ production from cardiomyocytes was determined using the oxidation of the fluorogenic indicator Amplex red in the presence of horseradish peroxidase (HRP) (Zhou et al. 1997). In the presence of peroxidase Amplex red reagent reacts with hydrogen peroxide in a 1:1 stoichiometry to produce the red fluorescent oxidation product resorufin. Briefly, cardiomyocytes were initially lysed by three cycles of freeze-thawing, which was followed by centrifugation at $3,000 \times g$ for $10 \mathrm{~min}$ at $4{ }^{\circ} \mathrm{C}$. $50 \mu \mathrm{l}$ of supernatant was reacted with $50 \mu \mathrm{l}$ of working solution containing $100 \mu \mathrm{mol} \cdot \mathrm{l}^{-1}$ Amplex red (Invitrogen) reagent and $0.2 \mathrm{U} \cdot \mathrm{ml}^{-1} \mathrm{HRP}$ (Sigma-Aldrich) in a $1 \times$ reaction buffer $\left(0.05 \mathrm{~mol} \cdot \mathrm{l}^{-1} \mathrm{Na}_{2} \mathrm{HPO}_{4}, \mathrm{pH} 7.4\right)$ and was incubated at 
room temperature for $30 \mathrm{~min}$ in the dark. Fluorescence was monitored on a reader (Tecan Infinite M200, Tecan, Austria) with excitation at $570 \mathrm{~nm}$ and emission at $585 \mathrm{~nm}$. Micromoles of $\mathrm{H}_{2} \mathrm{O}_{2}$ were calculated using a standard curve generated from the readings of various concentrations of $\mathrm{H}_{2} \mathrm{O}_{2}\left(0-10 \mu \mathrm{mol} \cdot \mathrm{l}^{-1}\right)$. The results were expressed as micromoles per milligram of protein. Each experiment was performed in triplicate and independently repeated at least six times.

\section{FTSC fluorometric assay of protein carbonyls}

Fluorescein 5-thiosemicarbazide

(FTSC) specifically reacts with carbonyl groups in oxidized proteins and not in oxidized lipids. Cells were washed once with PBS and scraped into PBS (100 $\mu \mathrm{l})$. $50 \mu \mathrm{l}$ samples were reacted with an equal volume of $0.2 \mathrm{mmol} \cdot \mathrm{l}^{-1}$ FTSC overnight in the dark. Proteins were precipitated by the addition of 4 volumes of ice-cold $20 \%$ TCA $(400 \mu \mathrm{l})$. Following $10 \mathrm{~min}$ of incubation on ice, tubes were centrifuged at $12,000 \times g$ for $10 \mathrm{~min}$ at $4{ }^{\circ} \mathrm{C}$. Supernatants were carefully decanted; precipitates were washed three times by vortexing with $1 \mathrm{ml}$ of aceton and centrifuged immediately. Finally, acetone supernatant was carefully decanted and protein precipitates were air-dried, solubilized with $50 \mu \mathrm{l}$ of $6 \mathrm{~mol} \cdot \mathrm{l}^{-1}$ Guanidyl hydrochloride, and diluted 10 -fold by the addition of $450 \mu \mathrm{l}$ of $0.1 \mathrm{~mol} \cdot \mathrm{l}^{-1} \quad \mathrm{NaH}_{2} \mathrm{PO}_{4} \quad(\mathrm{pH} 7.0)$. Protein concentration in each of these samples was measured by the BCA assay, which requires that guanidyl hydrochloride be less than $4 \mathrm{~mol}^{-1} \mathrm{l}^{-1}$. The samples were aliquoted $100 \mu \mathrm{l}$ per well in triplicate into microtiter plate, and fluorescence was measured in a reader (Tecan Infinite M200, Tecan, Austria) with excitation at $485 \mathrm{~nm}$ and emission at $535 \mathrm{~nm}$. Fluorescence readings from six wells for each sample were averaged, and nanomoles of FTSC-reacted carbonyls were calculated using a standard curve generated from the readings of various concentrations of FTSC prepared in medium similar to that of samples (Mohanty et al. 2010). The results were expressed as micromoles per milligram of protein. Each experiment was performed in triplicate and independently repeated at least six times.

\section{Western blotting analysis}

Total proteins were prepared from rat neonatal cardiomyocytes in RIPA buffer (in $\mathrm{mmol} \cdot \mathrm{l}^{-1}$ : $150 \mathrm{NaCl}$, 10 Tris, 5 EDTA, $0.1 \mathrm{Na}_{3} \mathrm{VO}_{4}, \quad 1 \mathrm{NaF}, \quad 1 \%$ sodium deoxycholate, $10 \%$ SDS, $1 \%$ Triton X-100, 1 protease inhibitor cocktail tablet) and incubated at $4{ }^{\circ} \mathrm{C}$ for
$30 \mathrm{~min}$. The extracts were later centrifuged at $12000 \mathrm{rpm}$ at $4{ }^{\circ} \mathrm{C}$ for $15 \mathrm{~min}$. Equal amounts of total protein $(20 \mu \mathrm{g})$ were boiled and separated with SDS-PAGE and electophoretically transferred to a PVDF membrane. Membranes were blocked with Tris-buffered salineTween 20 buffer (TBST) containing $5 \%$ non-fat milk at room temperature for $2 \mathrm{~h}$, and then incubated overnight at $4{ }^{\circ} \mathrm{C}$ with primary antibodies. The primary antibody dilutions were 1:2000 for Actin (goat, sc-1616, Santa Cruz), 1:500 for p-PKCe Ser 729 (goat, sc-12355, Santa Cruz) and 1:500 for PKCe C-15 (rabbit, sc-214, Santa Cruz). The membrane was then washed three times with TBST buffer and incubated in TBST buffer containing $5 \%$ non-fat milk with secondary antibody (diluted 1:5000, Santa Cruz) for $1 \mathrm{~h}$ at room temperature. Finally, the membrane was washed with TBST for three times. For detection, the membranes were saturated with an enhanced chemiluminescence mixture for $1 \mathrm{~min}$ and viewed by autography using preflashed X-ray film (Kodak Scientific Imaging film) for $60 \mathrm{~s}$. The bands were analyzed by densitometric scanning using Typhoon 9400 scanner.

\section{Statistics}

Analysis of variance with post-hoc Tukey test was applied using STATISTICA software (StatSoft). $\mathrm{p}<0.05$ was considered statistically significant.

\section{Results}

DHS modulates cardiomyocyte viability and $L D H$ release We monitored cell viability by flow cytometry and LDH activity in the culture medium to evaluate the general effects of hypoxia and reoxygenation on neonatal rat cardiomyocytes. Hypoxia/reoxygenation significantly increased the number of dead cardiomyocytes as evidenced by an elevated peak of sub-G1 fraction (H/Re vs ctrl group, $\left.{ }^{*} \mathrm{p}<0.001\right)$ compared with the control group (Fig. 2). When cardiomyocytes were treated at the onset of reoxygenation with DHS $\left(10 \mu \mathrm{mol} \cdot \mathrm{l}^{-1}, 10 \mathrm{~min}\right)$ the number of dead cardiomyocytes was reduced compared with the hypoxia/reoxygenation group (DHS vs H/Re group, $\left.{ }^{\dagger} \mathrm{p}<0.001\right)$. The dose and exposure time for DHS treatment were selected based on our previous studies, which revealed the ability of DHS to suppress ROS formation (Gabrielova et al. 2010). Pilot experiments verified that lower concentrations of DHS display the same protective activity in dose-dependent fashion but were not statistically significant. 


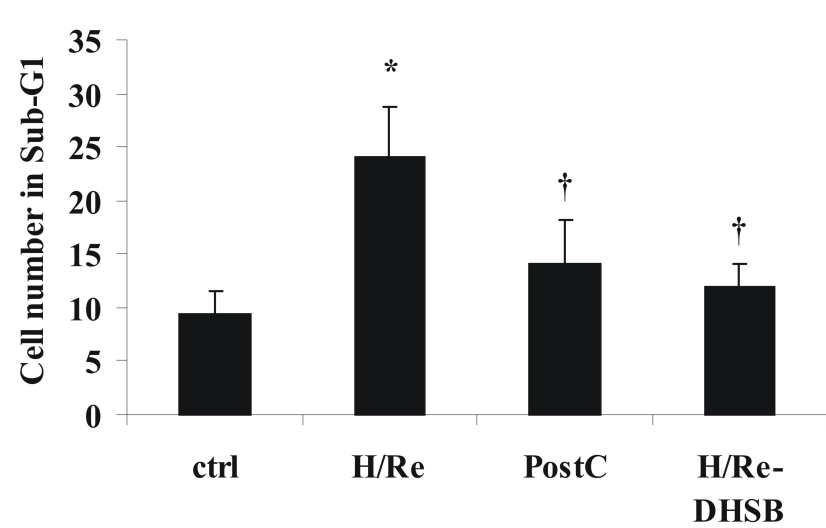

Fig. 2. Flow cytometric analysis of cell death in primary rat neonatal cardiomyocytes. Flow cytometric analysis of primary neonatal rat cardiomyocyte death was performed in the control (ctrl), hypoxia/reoxygenation ( $\mathrm{H} / \mathrm{Re})$, postconditioning (PostC) and hypoxia/reoxygenation with $10 \mu \mathrm{mol}^{\cdot} \mathrm{l}^{-1} \mathrm{DHS}$ (DHS) groups. The number of total cell death was determined by propidium iodide staining as mentioned in section Methods. The percentageof cells in sub-G1 peak were calculated using MultiCycle AV Software. The data are means \pm SEM of four independent experiments. ${ }^{*} p<0.001$ vs ctrl group, ${ }^{+} p<0.001$ vs $\mathrm{H} / \mathrm{Re}$ group.

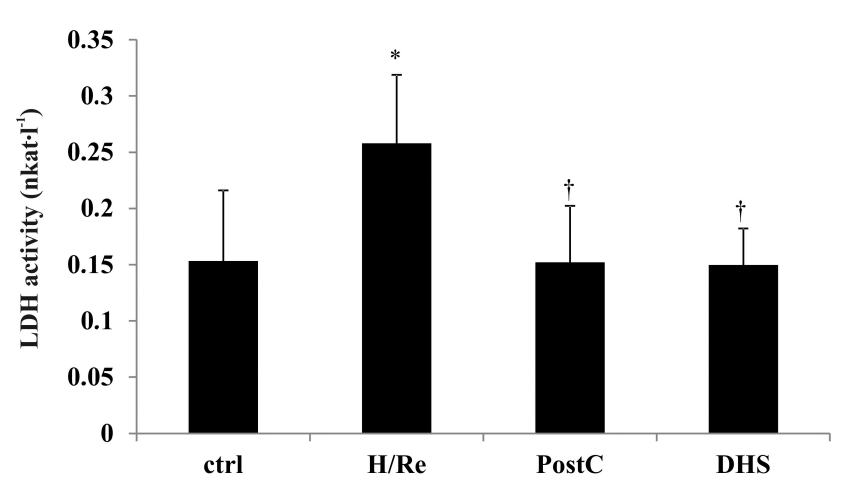

Fig. 3. Effect of DHS on LDH leakage in cardiomyocytes exposed to hypoxia/reoxygenation. The activity of lactate dehydrogenase $(\mathrm{LDH})$ released into the culture medium via cell membrane disruption was measured spectrophotometrically at $340 \mathrm{~nm}$ in control (ctrl), hypoxia/reoxygenation $(\mathrm{H} / \mathrm{Re})$, postconditioning (PostC) and hypoxia/reoxygenation with DHS (DHS) groups. Cell cultures of neonatal rat cardiomyocytes were exposed to DHS $\left(10 \mu \mathrm{mol} \cdot \mathrm{l}^{-1}, 10 \mathrm{~min}\right)$ in $\mathrm{H} / \mathrm{Re}$ group after $3 \mathrm{~h}$ of hypoxia. The viability of treated cells was expressed in nkat per liter. The data are means \pm SEM of six independent experiments. ${ }^{*} p<0.001$ vs ctrl group, ${ }^{\dagger} p<0.001$ vs $H / R e$ group.

LDH activity in the culture medium was used as an indicator of cytotoxicity. A significant increase of $\mathrm{LDH}$ released $\left(\mathrm{H} / \mathrm{Re}\right.$ vs ctrl group; $\left.{ }^{*} \mathrm{p}<0.001\right)$ was detected in the hypoxia/reoxygenation group versus the control group (Fig. 3). LDH leakage in the medium was reduced when cardiomyocytes were postconditioned before full reoxygenation (PostC vs H/Re group, $\left.{ }^{\dagger} \mathrm{p}<0.001\right)$. DHS treatment significantly diminished the $\mathrm{H} / \mathrm{Re}$-induced LDH release (DHS vs H/Re group, ${ }^{\dagger} \mathrm{p}<0.001$; Fig. 3).

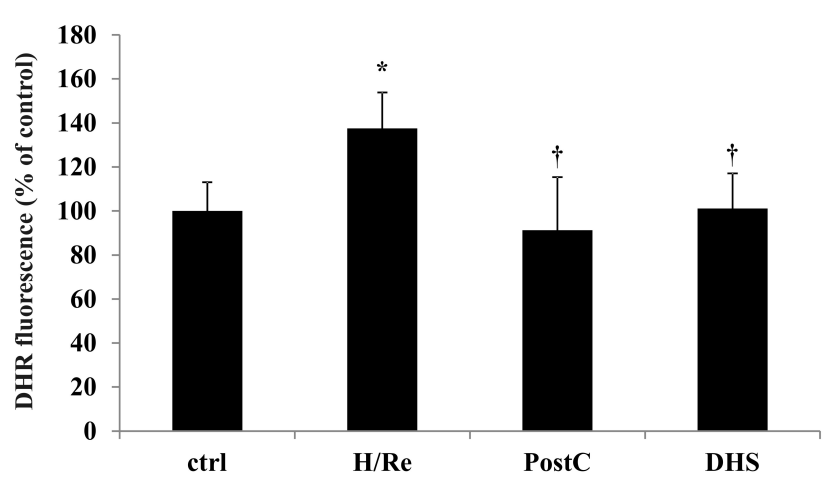

Fig. 4. ROS production decreases in hypoxia/reoxygenation group after DHS treatment. Reactive oxygen species (ROS) production was measured using fluorescence probe dihydrorhodamine 123 (DHR) in control (ctrl), hypoxia/reoxygenation (H/Re), postconditioning (PostC) and hypoxia/reoxygenation with DHS (DHS) groups. We have used DHS (10 $\left.\mu \mathrm{mol} \cdot \mathrm{l}^{-1}, 10 \mathrm{~min}\right)$ for treatment of rat neonatal cardiomyocytes after $3 \mathrm{~h}$ of hypoxia. The fluorescence is monitored at specific excitation/emission wavelengths $488 / 525 \mathrm{~nm}$. The results were expressed as fluorescence of DHR per milligram of protein. The data are means \pm SEM of eight independent experiments ${ }^{*} p<0.001$ vs ctrl group, ${ }^{\dagger} \mathrm{p}<0.001 \mathrm{vs} \mathrm{H/Re}$ group.

DHS attenuates production of reactive oxygen and nitrogen species

Reoxygenation is associated with elevated ROS formation therefore we employed an oxidation-sensitive fluorescent probe dihydrorhodamine to assess changes in intracellular ROS and reactive nitrogen species (RNS) levels. Cellular oxidative stress was increased as a result of hypoxia/reoxygenation treatment (H/Re vs ctrl group, $\left.{ }^{*} \mathrm{p}<0.001\right)$ in comparison with the postconditioned cardiomyocytes (PostC vs H/Re group, ${ }^{\dagger} \mathrm{p}<0.001$ ). The increase of ROS/RNS formation was significantly diminished by $10 \mu \mathrm{mol} \cdot \mathrm{l}^{-1}$ DHS (DHS vs H/Re group, ${ }^{\dagger} \mathrm{p}<0.001$; Fig. 4).

\section{DHS diminishes formation of hydrogen peroxide}

Although a variety of ROS are present in a cell, hydrogen peroxide, formed by superoxide dismutase inside and outside of mitochondria, is of particular interest as it can diffuse through cellular membranes and interact with various cellular compartments. The $\mathrm{H}_{2} \mathrm{O}_{2}$ generation was detectable after $9 \mathrm{~h}$ of incubation in the control group but was significantly increased in hypoxic/reoxygenated cardiomyocytes relative to control cells (H/Re vs ctrl group, ${ }^{*} \mathrm{p}<0.001$; Fig. 5). The level of hydrogen peroxide after $6 \mathrm{~h}$ of reoxygenation was significantly decreased in the group of cardiomyocytes treated with three cycles of postconditioning (PostC vs $\mathrm{H} / \mathrm{Re}$ group, ${ }^{\dagger} \mathrm{p}<0.001$ ) with a similar effect present in the cardiomyocytes treated with $10 \mu \mathrm{mol} \cdot \mathrm{l}^{-1}$ DHS for $10 \mathrm{~min}$ (DHS vs H/Re group, $\left.{ }^{\dagger} \mathrm{p}<0.001\right)$. 


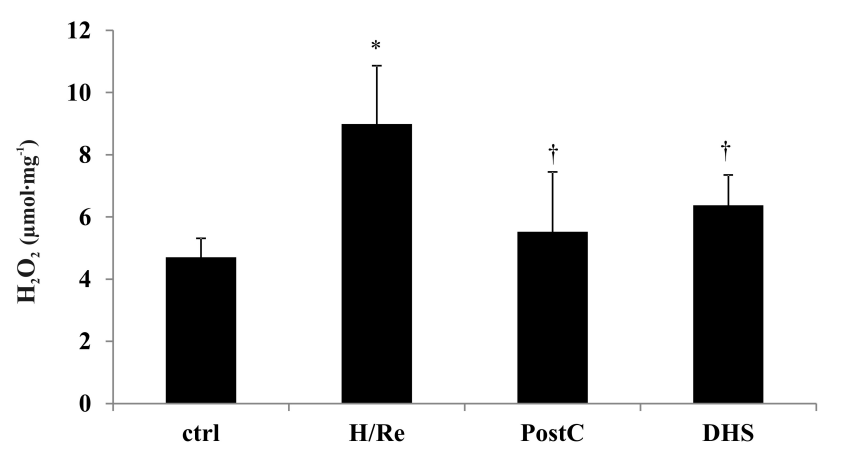

Fig. 5. DHS decreases $\mathrm{H}_{2} \mathrm{O}_{2}$ level in cardiomyocytes exposed to hypoxia/reoxygenation. The $\mathrm{H}_{2} \mathrm{O}_{2}$ production from cardiomyocytes was determined using the oxidation of the fluorogenic indicator Amplex red in the presence of horseradish peroxidase in control (ctrl), hypoxia/reoxygenation $(\mathrm{H} / \mathrm{Re})$, postconditioning (PostC) and hypoxia/reoxygenation with $10 \mu \mathrm{mol} \cdot \mathrm{l}^{-1}$ DHS (DHS) groups. Fluorescence was monitored on a reader with excitation at $570 \mathrm{~nm}$ and emission at $585 \mathrm{~nm}$. Micromoles of $\mathrm{H}_{2} \mathrm{O}_{2}$ were calculated using a standard curve and related to a milligram of protein. The data are means \pm SEM of eight independent experiments. ${ }^{*} p<0.001$ vs ctrl group, ${ }^{\dagger} p<0.001$ vs $\mathrm{H} / \mathrm{Re}$ group.

\section{DHS decreases formation of protein carbonyls}

The detected increase in ROS formation indicates a potential oxidative damage to the cell while measurement of selected markers of oxidative stress indicates the target of ROS-mediated damage. The detection of protein carbonylation is frequently used as a marker of irreversible protein oxidative modification. Recent reports (Chaudhuri et al. 2006, Fujita et al. 2007) have used a highly fluorescent compound, fluorescein 5-thiosemicarbazide (FTSC) that specifically reacts with carbonyl groups in oxidized proteins and not in oxidized lipids. A semi-microplate format assay of protein carbonyls using this FTSC-carbonyl reaction was developed (Mohanty et al. 2010). It measures directly the protein carbonyls similarly to the classical spectrophotometric assay and gives results comparable to the latter method. A significant increase of carbonyl groups $\left(\mathrm{H} / \mathrm{Re}\right.$ vs ctrl group, $\left.{ }^{*} \mathrm{p}<0.001\right)$ in oxidized proteins was detected in the hypoxia/reoxygenation group (Fig. 6). The concentration of protein carbonyls was reduced (PostC vs $\mathrm{H} / \mathrm{Re}$ group, ${ }^{\dagger} \mathrm{p}<0.001$ ) when cardiomyocytes were postconditioned before full reoxygenation. $10 \mu \mathrm{mol} \cdot \mathrm{l}^{-1} \mathrm{DHS}$ treatment after hypoxia also significantly inhibited $\mathrm{H} / \mathrm{Re}$-induced increase of protein carbonyls (DHS vs $\mathrm{H} / \mathrm{Re},{ }^{\dagger} \mathrm{p}<0.001$ ).

\section{DHS restores the phosphorylated/total PKCE ratio}

To investigate whether $\mathrm{PKC} \varepsilon$ was involved in DHS-induced cardioprotection, the levels of PKC $\varepsilon$ were evaluated using western blotting analysis. Because one of

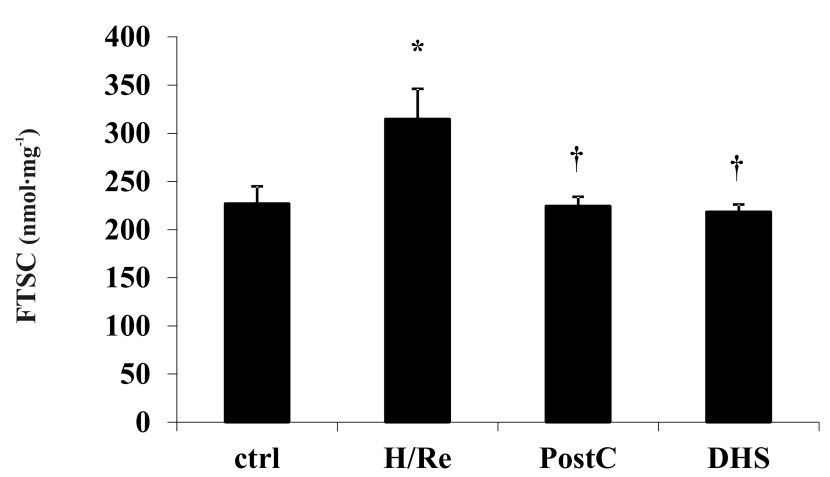

Fig. 6. Effect of DHS on protein carbonyls in hypoxia/ reoxygenated cardiomyocytes. Protein carbonyls were detected by fluorescent probe fluorescein-5-thiosemicarbazide (FTSC) in control (ctrl), hypoxia/reoxygenation $(\mathrm{H} / \mathrm{Re})$, postconditioning (PostC) and hypoxia/reoxygenation with $10 \mu \mathrm{mol} \cdot \mathrm{l}^{-1} \mathrm{DHS}$ (DHS) groups. The fluorescence is monitored at specific excitation/ emission wavelengths $485 / 535 \mathrm{~nm}$. Nanomoles of FTSC-reacted carbonyls were calculated using a standard curve and related to a milligram of protein. The data are means \pm SEM of four independent experiments. ${ }^{*} p<0.001$ vs ctrl group, ${ }^{\dagger} p<0.001$ vs $\mathrm{H} / \mathrm{Re}$ group.

the active $\mathrm{PKC} \varepsilon$ is phosphorylated on Ser 729, we detected both total and phosphorylated PKC $\varepsilon$ (p-PKC $\varepsilon$ ) in control, $\mathrm{H} / \mathrm{Re}$, PostC and DHS-treated $\left(10 \mu \mathrm{mol} \cdot \mathrm{l}^{-1}\right.$, $10 \mathrm{~min}$ ) groups using general and Ser 729 phosphospecific antibodies (Fig. 7A). The intensity of each band was quantified by densitometry and the ratio of pPKC $\varepsilon / P K C \varepsilon$ was calculated from the data obtained by scanning and then normalized to the actin signal (Fig. 7B). The data show a significant decrease in the pPKCE/PKCE ratio in the hypoxia/reoxygenation group compared to the control $(\mathrm{H} / \mathrm{Re}$ vs control group, $\left.{ }^{*} \mathrm{p}<0.001\right)$ while both the postconditioning protocol and the DHS treatment significantly increased the pPKC $\varepsilon / \mathrm{PKC} \varepsilon$ ratio relative to the $\mathrm{H} / \mathrm{Re}$ group (PostC vs $\mathrm{H} / \mathrm{Re}$ group, DHS vs H/Re group, $\left.{ }^{\dagger} \mathrm{p}<0.001\right)$ and restored the pPKC $8 / \mathrm{PKC} \varepsilon$ ratio to the levels of the control.

\section{Discussion}

Ischemia/reperfusion is the culprit in the eventual fatal damage to the heart muscle. Although cells are capable of adapting to lower oxygen conditions, adaptive mechanisms to deal with sudden reoxygenation are rather slow. Preventing the ischemic conditions is therefore desirable. However, it is very difficult to achieve, as in majority of cases we only find out about the occurrence after. Both postconditioning and pharmacological postconditioning aim at minimizing the damage arising from the index ischemia. 
A

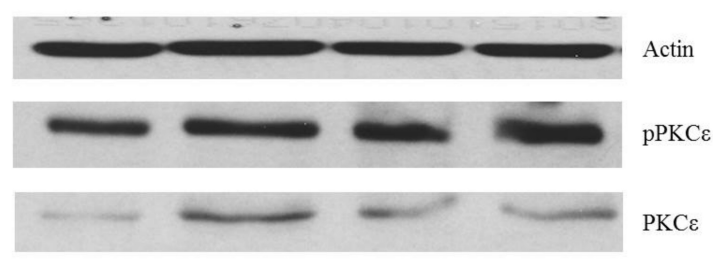

B

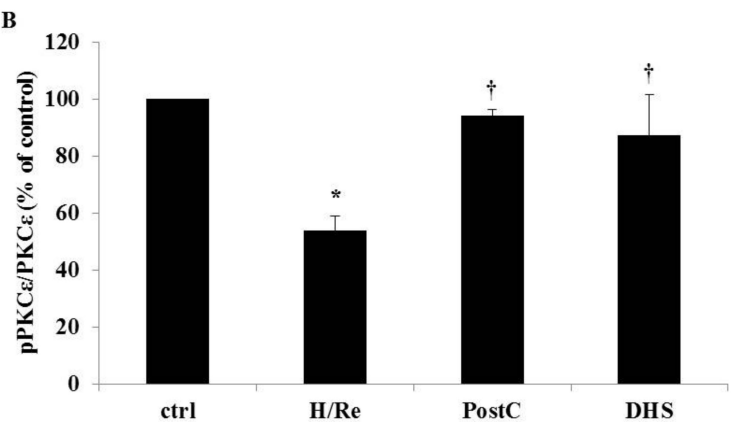

Fig. 7. Effect of postconditioning and DHS on protein kinase $C$ epsilon $(\mathrm{PKC} \varepsilon)$ phosphorylation status in rat primary cardiomyocytes after simulated hypoxia/reoxygenation injury. pPKC $\varepsilon$ and PKC $\varepsilon$ protein bands were detected in total cell lysates of control (ctrl), hypoxia/reoxygenation $(\mathrm{H} / \mathrm{Re})$, postconditioning (PostC) and hypoxia/reoxygenation with $\left.10 \mu \mathrm{mol}^{-1}\right|^{-1}$ DHS (DHS) groups. A. Representative western blot using total PKCE (PKCE) and Ser 729 phosphospecific (pPKC $\varepsilon$ ) antibodies. B. The intensity of each band was quantified by densitometry, ratio of pPKC $\varepsilon / P K C \varepsilon$ was calculated according to the result obtained from scan and data were normalized to the actin signal. The data are means \pm SEM of three independent experiments. ${ }^{*} p<0.001$ vs ctrl group, ${ }^{+} \mathrm{p}<0.001 \mathrm{vs} \mathrm{H} / \mathrm{Re}$ group.

Postconditioning denotes a conditioning in which a decrease in the infarct size results from brief periods of ischemia applied during reperfusion, immediately following an ischemic insult (VintenJohansen 2007, Hausenloy and Yellon 2008). Postconditioning may reduce apoptosis, necrosis, and endothelial dysfunction/activation, thus leading to a reduced endothelium/leukocyte interaction and to reduced ROS inflammatory formation (Skyschally et al. 2009, Vinten-Johansen et al. 2010). Mechanisms of protection by ischemic postconditioning have been studied in detail in the mammalian heart, in vitro and in vivo, and a number of themes have emerged. There is the involvement of endogenous cell-surface ligands such as adenosine, bradykinin, and opioids, which trigger protection by activating multiple intermediate kinase pathways. In fact, both preconditioning and postconditioning induce activation of signaling elements during the early reperfusion following the index ischemia (for review see Garlid et al. 2009). Pharmacological postconditioning involves the application of a pharmacological agent as soon as possible following the hypoxia period. Therefore, studies focused on the development of novel agents with protective activities against hypoxia/reoxygenation damage are of great interest.

Natural polyphenolic compounds display various cytoprotective activities and have been linked to cardioprotection (Fraga et al. 2010). Recent experimental data demonstrate that natural polyphenols can exert its cardioprotective effect via the activation of several prosurvival cellular pathways (Lecour and Lamont 2011), however a definitive understanding of the mechanisms behind the cardioprotective effect of polyphenols is still a matter of ongoing investigation.

Our previous study evaluated cardioprotective effects of SB, DHS, and some of their derivatives and demonstrated that DHS displays activity in cardiomyocytes similar to that of synthetic uncouplers of oxidative phosphorylation. We have demonstrated that DHS attenuates the production of ROS in cardiomyocyte mitochondria by a mechanism which involves the uncoupling of the mitochondrial protonmotive force from the synthesis of ATP (Gabrielova et al. 2010). We inferred that DHS protects cardiomyocytes against ROS-mediated damage thanks to its uncoupler-like behavior (Gabrielova et al. 2010). Our working hypothesis states that this very behavior may assist the cells in dealing with the increase in oxygen inflow following reoxygenation because it triggers a demand for oxygen while keeping ROS formation at or close to physiological levels thus maintaining the signaling role of ROS.

Here we demonstrate that a brief treatment with a single dose of DHS has beneficial effect in the model of rat neonatal cardiomyocytes when cell death resulting from hypoxia/reoxygenation is diminished with concurrent modulation of ROS and ROS-dependent damage. Because DHS decreases mitochondrial ROS formation while increasing oxygen consumption accompanied by mitochondrial membrane potential decrease (Gabrielova et al. 2010), we questioned whether DHS may be capable of preventing oxidative damage due to reoxygenation in comparison with postconditioning. The evidence we present supports the role of DHS as a postconditioning mimic because in all aspects we evaluated, DHS showed the same or a very similar effect as postconditioning. The important aspect of DHS treatment is the time frame, where only ten minutes of treatment were sufficient to evoke an effect mimicking that of postconditioning.

DHS, a silybin derivative, was originally 
isolated as a minor component of the extract from seeds of the Silybum marianum subsp. anatolicum. This flavonolignan has multiple biological properties connected with its radical scavenging activity (Gazak et al. 2009). Although the radical scavenging ability and pharmacology of silybin (SB) were studied extensively, the molecular mechanisms of the antioxidant activity of SB and DHS were not systematically investigated and remain unclear. Two studies investigated the role of individual hydroxyl groups in SB and DHS in antiradical activity (Trouillas et al. 2008, Gazak et al. 2009). In this case selectively methylated derivatives of SB and DHS were prepared and tested for their ability to interact directly with a radical. It was determined that C-20 hydroxyl group in SB and C-3 and C-20 hydroxyl groups of DHS are responsible for the interaction with radicals. However, direct interaction of the flavonolignans with radicals need not be the only or even the decisive mechanism of cytoprotective activity resulting in ROS modulation.

Here we show that DSH is very effective in ROS modulation, hence preventing hypoxia/reoxygenation damage in rat neonatal cardiomyocytes. The importance of a reduced endothelial activation, neutrophil adherence and consequently redox-sensible mechanisms in postconditioning was shown (Zhao et al. 2003). A reduction in superoxide anion generation was observed in the proximity of risk area in postconditioned hearts (Halkos et al. 2004, Iliodromitis et al. 2006). These findings of reduced ROS production in postconditioning are in line with the idea that massive ROS production is implicated in the sequelae of myocardial reperfusion injury.

Protein kinase $\mathrm{C}$ epsilon is a member of group of the PKC family of serine and threonine kinases that are involved in a wide range of physiological processes, including mitogenesis (Yan et al. 2013), cell survival under stressful conditions, metastasis (Gorin and Pan 2009) and transcriptional regulation (Lin et al. 2011). Thus far, PKCE has been shown to be critical for cardiac protection during $\mathrm{H} / \mathrm{Re}$ injury (reviewed in Budas et al. 2007). Postconditioning was associated with significantly higher PKCE levels in areas of the myocardium at risk and selective isoform inhibition prevented the infarct size reduction (Zatta et al. 2006). Moreover, the protective effects of ischemic postconditioning were shown to be dependent on PKCE using both the isolated heart model (Philipp et al. 2006, Zatta et al. 2006) and isolated neonatal cardiomyocytes (Dong et al. 2010). PKCE is activated by a series of phosphorylations in the catalytic domain at Thr566, Thr710 and Ser729 (Newton 2001). Phosphorylation at Ser729 increases in cardioprotection (Zhou et al. 2002) and loss of the Ser729 phosphate is associated with $\mathrm{PKC} \varepsilon$ translocation to the cell periphery or nucleus (Xu et al. 2007).

On the basis of these findings, we investigated whether DHS treatment protected cardiomyocytes from simulated hypoxia/reoxygenation injury via a signaling pathway involving $\mathrm{PKC} \varepsilon$. Western blotting using antibodies to detect the total levels of PKCE and phosphospecific antibodies to detect the Ser 729 phosphorylated PKCE demonstrated that DHS treatment restored the phosphorylated/total PKCE ratio in cardiomyocytes exposed to H/Re (Fig. 7). Following the hypoxia/reoxygenation protocol, our results show a significant decrease in the Ser729-phosphorylated PKCE relative to the total $\mathrm{PKC} \varepsilon$. Both postconditioning and DHS treatment attenuated such a decrease. These results suggest that both postconditioning and DHS treatment affect the phosphorylation status of PKCe following the hypoxia/reoxygenation in rat primary cardiomyocytes and are consistent with the effects of postconditioning on pPKCE levels observed during myocardial and cerebral ischemia (Zatta et al. 2006, Gao et al. 2008). We conclude that DHS treatment could regulate the activity and phosphorylation status of $\mathrm{PKC} \varepsilon$ protein.

\section{Conclusion}

Our study demonstrates that DHS treatment reduces cell death in isolated rat neonatal cardiomyocytes after hypoxia/reoxygenation. The attenuation of cellular oxidative stress suggests that this is the main mechanism of the protective activity of DHS. Our data also show that DHS treatment altered the $\mathrm{pPKC} / \mathrm{PKC} \varepsilon$ ratio, which indicates that DHS may mimic the effect of postconditioning by interacting with the PKCE-dependent cardioprotective pathways. The immediacy of the effect and the low micromolar concentration of DHS are promising for a possible pharmacological use. However, additional studies are required to clarify the mechanism operative.

\section{Conflict of Interest}

There is no conflict of interest.

\section{Acknowledgements}

The authors would like to thank Petr Doležal and Jiří 
Novotný from the Department of Biology, Palacky University in Olomouc for their expert assistance with the flow cytometry based cell death assay. This work was supported by the Czech Science Foundation (GACR 301/11/0662), and the Operational Program Research and Development for Innovations - European Social Fund (CZ.1.05/2.1.00/01.0030).

\section{Abbreviations}

DHS, 2,3-dehydrosilybin; DHR, dihydrorhodamine 123; FTSC, fluorescein-5-thiosemicarbazide; H/Re, hypoxia/ reoxygenation; PI, propidium iodide; ROS, reactive oxygen species; SB, silybin.

\section{References}

AGARWAL R, AGARWAL C, ICHIKAWA H, SINGH RP, AGGARWAL BB: Anticancerpotential of silymarin: from bench to bed side. Anticancer Res 26: 4457-4498, 2006.

BECKER LB, VANDEN HOEK TL, SHAO ZH, LI CQ, SCHUMACKER PT: Generation of superoxide in cardiomyocytes during ischemia before reperfusion. Am J Physiol 277: H2240-H2246, 1999.

BRADFORD MM: A rapid and sensitive method for the quantitation of microgram quantities of protein utilizing the principle of protein-dye binding. Anal Biochem 72: 248-254, 1976.

BUCHHOLZ B, DONATO M, D'ANNUNZIO V, GELPI R: Ischemic postconditioning: mechanisms, comorbidities, and clinical application. Mol Cell Biochem 392: 1-12, 2014.

BUDAS GR, CHURCHILL EN, MOCHLY-ROSEN D: Cardioprotective mechanisms of PKC isozyme-selective activators and inhibitors in the treatment of ischemia-reperfusion injury. Pharmacol Res 55: 523-536, 2007.

CADENAS E: Biochemistry of oxygen toxicity. Annu Rev Biochem 58: 79-110, 1989.

CELIK H, ARINC E: Evaluation of the protective effects of quercetin, rutin, naringenin, resveratrol and trolox against idarubicin-induced DNA damage. J Pharm Pharm Sci 13: 231-241, 2010.

CHAUDHURI AR, DE WAAL EM, PIERCE A, VAN REMMEN H, WARD WF, RICHARDSON A: Detection of protein carbonyls in aging liver tissue: a fluorescence-based proteomic approach. Mech Ageing Dev 127: 849-861, 2006.

CHLOPCIKOVA S, PSOTOVA J, MIKETOVA P: Neonatal rat cardiomyocytes - a model for the study of morphological, biochemical and electrophysiological characteristics of the heart. Biomed Pap Med Fac Univ Palacky Olomouc Czech Repub 145: 49-55, 2001.

COMELLI MC, MENGS U, SCHNEIDER C, PROSDOCIMI M: Toward the definition of the mechanism of action of silymarin: activities related to cellular protection from toxic damage induced by chemotherapy. Integr Cancer Ther 6: 120-129, 2007.

DING T, TIAN S, ZHANG Z, GU D, CHEN Y, SHI Y, SUN Z: Determination of active component in silymarin by RP-LC and LC/MS. J Pharm Biomed Anal 26: 155-161, 2001.

DONG S, TENG Z, LU FH, ZHAO YJ, LI H, REN H, CHEN H, PAN ZW, LV YJ, YANG BF, TIAN Y, XU CQ, ZHANG WH: Post-conditioning protects cardiomyocytes from apoptosis via PKC(epsilon)-interacting with calcium-sensing receptors to inhibit endo(sarco)plasmic reticulum-mitochondria crosstalk. Mol Cell Biochem 341: 195-206, 2010.

FRAGA CG, GALLEANO M, VERSTRAETEN SV, OTEIZA PI: Basic biochemical mechanisms behind the health benefits of polyphenols. Mol Aspects Med 31: 435-445, 2010.

FUJITA H, HIRAO T, TAKAHASHI M: A simple and non-invasive visualization for assessment of carbonylated protein in the stratum corneum. Skin Res Technol 13: 84-90, 2007.

GABRIELOVA E, JABUREK M, GAZAK R, VOSTALOVA J, JEZEK J, KREN V, MODRIANSKY M: Dehydrosilybin attenuates the production of ROS in rat cardiomyocyte mitochondria with an uncoupler-like mechanism. J Bioenerg Biomembr 42: 499-509, 2010.

GAO X, ZHANG H, TAKAHASHI T, HSIEH J, LIAO J, STEINBERG GK, ZHAO H: The Akt signaling pathway contributes to postconditioning's protection against stroke; the protection is associated with the MAPK and PKC pathways. J Neurochem 105: 943-955, 2008. 
GARCIA S, HENRY TD, WANG YL, CHAVEZ IJ, PEDERSEN WR, LESSER JR, SHROFF GR, MOORE L, TRAVERSE JH: Long-term follow-up of patients undergoing postconditioning during ST-elevation myocardial infarction. J Cardiovasc Transl Res 4: 92-98, 2010.

GARLID KD, COSTA AD, QUINLAN CL, PIERRE SV, DOS SANTOS P: Cardioprotective signaling to mitochondria. J Mol Cell Cardiol 46: 858-866, 2009.

GAZAK R, SEDMERA P, VRBACKY M, VOSTALOVA J, DRAHOTA Z, MARHOL P, WALTEROVA D, KREN V: Molecular mechanisms of silybin and 2,3-dehydrosilybin antiradical activity - role of individual hydroxyl groups. Free Radic Biol Med 46: 745-758, 2009.

GAŽÁK R, TROUILLAS P, BIEDERMANN D, FUKSOVÁ K, MARHOL P, KUZMA M, KŘEN V: Base-catalyzed oxidation of silybin and isosilybin into 2,3-dehydro derivatives. Tetrahedron Letters 54: 315-317, 2013.

GORIN MA, PAN Q: Protein kinase C epsilon: an oncogene and emerging tumor biomarker. Mol Cancer 8: 9, 2009.

GUAIQUIL VH, GOLDE DW, BECKLES DL, MASCARENO EJ, SIDDIQUI MA: Vitamin C inhibits hypoxiainduced damage and apoptotic signaling pathways in cardiomyocytes and ischemic hearts. Free Radic Biol Med 37: 1419-1429, 2004.

HALKOS ME, KERENDI F, CORVERA JS, WANG NP, KIN H, PAYNE CS, SUN HY, GUYTON RA, VINTENJOHANSEN J, ZHAO ZQ: Myocardial protection with postconditioning is not enhanced by ischemic preconditioning. Ann Thorac Surg 78: 961-969, 2004.

HAUSENLOY DJ, YELLON DM: Preconditioning and postconditioning: new strategies for cardioprotection. Diabetes Obes Metab 10: 451-459, 2008.

ILIODROMITIS EK, GEORGIADIS M, COHEN MV, DOWNEY JM, BOFILIS E, KREMASTINOS DT: Protection from post-conditioning depends on the number of short ischemic insults in anesthetized pigs. Basic Res Cardiol 101: 502-507, 2006.

KE N, WANG X, XU X, ABASSI YA: The xCELLigence system for real-time and label-free monitoring of cell viability. Methods Mol Biol 740: 33-43, 2011.

KIM DO, CHUN OK, KIM YJ, MOON HY, LEE CY: Quantification of polyphenolics and their antioxidant capacity in fresh plums. J Agric Food Chem 51: 6509-6515, 2003.

KREN V, MARHOL P, PURCHARTOVA K, GABRIELOVA E, MODRIANSKY M: Biotransformation of silybin and its congeners. Curr Drug Metab 14: 1009-1021, 2013.

KVASNICKA F, BIBA B, SEVCIK R, VOLDRICH M, KRATKA J: Analysis of the active components of silymarin. J Chromatogr A 990: 239-245, 2003.

LECOUR S, LAMONT KT: Natural polyphenols and cardioprotection. Mini Rev Med Chem 11: 1191-1199, 2011.

LIN HW, THOMPSON JW, MORRIS KC, PEREZ-PINZON MA: Signal transducers and activators of transcription: STATs-mediated mitochondrial neuroprotection. Antioxid Redox Signal 14: 1853-1861, 2011.

LONBORG J, KELBAEK H, VEJLSTRUP N, JORGENSEN E, HELQVIST S, SAUNAMAKI K, CLEMMENSEN P, HOLMVANG L, TREIMAN M, JENSEN JS, ENGSTROM T: Cardioprotective effects of ischemic postconditioning in patients treated with primary percutaneous coronary intervention, evaluated by magnetic resonance. Circ Cardiovasc Interv 3: 34-41, 2010.

MIURA T, TANNO M, SATO T: Mitochondrial kinase signalling pathways in myocardial protection from ischaemia/reperfusion-induced necrosis. Cardiovasc Res 88: 7-15, 2010.

MOHANTY JG, BHAMIDIPATY S, EVANS MK, RIFKIND JM: A fluorimetric semi-microplate format assay of protein carbonyls in blood plasma. Anal Biochem 400: 289-294, 2010.

NABAVI SM, NABAVI SF, MOGHADDAM AH, SETZER WN, MIRZAEI M: Effect of silymarin on sodium fluoride-induced toxicity and oxidative stress in rat cardiac tissues. An Acad Bras Cienc 84: 1121-1126, 2012.

NEWTON AC: Protein kinase C: structural and spatial regulation by phosphorylation, cofactors, and macromolecular interactions. Chem Rev 101: 2353-2364, 2001.

PHILIPP S, YANG XM, CUI L, DAVIS AM, DOWNEY JM, COHEN MV: Postconditioning protects rabbit hearts through a protein kinase C-adenosine A2b receptor cascade. Cardiovasc Res 70: 308-314, 2006.

PUERTOLLANO MA, PUERTOLLANO E, De CIENFUEGOS GA, DE PABLO MA: Dietary antioxidants: immunity and host defense. Curr Top Med Chem 11: 1752-1766, 2011. 
RAMBALDI A, JACOBS BP, IAQUINTO G, GLUUD C: Milk thistle for alcoholic and/or hepatitis B or C liver diseases - a systematic cochrane hepato-biliary group review with meta-analyses of randomized clinical trials. Am J Gastroenterol 100: 2583-2591, 2005.

RAO PR, VISWANATH RK: Cardioprotective activity of silymarin in ischemia-reperfusion-induced myocardial infarction in albino rats. Exp Clin Cardiol 12: 179-187, 2007.

SKYSCHALLY A, VAN CASTER P, ILIODROMITIS EK, SCHULZ R, KREMASTINOS DT, HEUSCH G: Ischemic postconditioning: experimental models and protocol algorithms. Basic Res Cardiol 104: 469-483, 2009.

SUN HY, WANG NP, KERENDI F, HALKOS M, KIN H, GUYTON RA, VINTEN-JOHANSEN J, ZHAO ZQ: Hypoxic postconditioning reduces cardiomyocyte loss by inhibiting ROS generation and intracellular $\mathrm{Ca} 2+$ overload. Am J Physiol Heart Circ Physiol 288: H1900-H1908, 2005.

SUN HY, WANG NP, HALKOS M, KERENDI F, KIN H, GUYTON RA, VINTEN-JOHANSEN J, ZHAO ZQ: Postconditioning attenuates cardiomyocyte apoptosis via inhibition of JNK and p38 mitogen-activated protein kinase signaling pathways. Apoptosis 11: 1583-1593, 2006.

TAGHIABADI E, IMENSHAHIDI M, ABNOUS K, MOSAFA F, SANKIAN M, MEMAR B, KARIMI G: Protective effect of silymarin against acrolein-induced cardiotoxicity in mice. Evid Based Complement Alternat Med 2012: 352091, 2012.

TANG L, LIU D, YI X, XU T, LIU Y, LUO Y, YIN D, HE M: The protective effects of puerarin in cardiomyocytes from anoxia/reoxygenation injury are mediated by PKCepsilon. Cell Biochem Funct 32: 378-386, 2014.

THIBAULT H, PIOT C, STAAT P, BONTEMPS L, SPORTOUCH C, RIOUFOL G, CUNG TT, BONNEFOY E, ANGOULVANT D, AUPETIT JF, FINET G, ANDRE-FOUET X, MACIA JC, RACZKA F, ROSSI R, ITTI R, KIRKORIAN G, DERUMEAUX G, OVIZE M: Long-term benefit of postconditioning. Circulation 117: 1037-1044, 2008.

TROUILLAS P, MARSAL P, SVOBODOVA A, VOSTALOVA J, GAZAK R, HRBAC J, SEDMERA P, KREN V, LAZZARONI R, DUROUX JL, WALTEROVA D: Mechanism of the antioxidant action of silybin and 2,3-dehydrosilybin flavonolignans: a joint experimental and theoretical study. $J$ Phys Chem A 112: 1054-1063, 2008.

TU RH, CHEN L, ZHONG GQ, ZENG ZY, LI QJ, HE Y, HE Y, LI JY: The effect of mitochondrial oxidative stress and the expression of Bcl-2 and Bax proteins on cardiomyocyte apoptosis during hypoxia postconditioning (in Chinese). Zhonghua Xin Xue Guan Bing Za Zhi 40: 516-521, 2012.

VANDEN HOEK TL, LI C, SHAO Z, SCHUMACKER PT, BECKER LB: Significant levels of oxidants are generated by isolated cardiomyocytes during ischemia prior to reperfusion. J Mol Cell Cardiol 29: 2571-2583, 1997.

VINTEN-JOHANSEN J: Postconditioning: a mechanical maneuver that triggers biological and molecular cardioprotective responses to reperfusion. Heart Fail Rev 12: 235-244, 2007.

VINTEN-JOHANSEN J, GRANFELDT A, MYKYTENKO J, UNDYALA VV, DONG Y, PRZYKLENK K: The multidimensional physiological responses to postconditioning. Antioxid Redox Signal 14: 791-810, 2010.

VRBA J, DOLEZEL P, VICAR J, ULRICHOVA J: Cytotoxic activity of sanguinarine and dihydrosanguinarine in human promyelocytic leukemia HL-60 cells. Toxicol In Vitro 23: 580-588, 2009.

WANG HC, ZHANG HF, GUO WY, SU H, ZHANG KR, LI QX, YAN W, MA XL, LOPEZ BL, CHRISTOPHER TA, GAO F: Hypoxic postconditioning enhances the survival and inhibits apoptosis of cardiomyocytes following reoxygenation: role of peroxynitrite formation. Apoptosis 11: 1453-1460, 2006.

WANG S, DUAN Y, SU D, LI W, TAN J, YANG D, WANG W, ZHAO Z, WANG X: Delta opioid peptide [D-Ala2, D-Leu5] enkephalin (DADLE) triggers postconditioning against transient forebrain ischemia. Eur J Pharmacol 658: 140-144, 2011.

WARBURG O, CHRISTIAN W, GRIESE A: Hydrogen-transferring coenzyme, its composition and mode of action. Biochem Z 282: 157-205, 1935.

WARDMAN P: Fluorescent and luminescent probes for measurement of oxidative and nitrosative species in cells and tissues: progress, pitfalls, and prospects. Free Radic Biol Med 43: 995-1022, 2007.

WARDMAN P: Methods to measure the reactivity of peroxynitrite-derived oxidants toward reduced fluoresceins and rhodamines. Methods Enzymol 441: 261-282, 2008.

WEIDMANN AE: Dihydroquercetin: More than just an impurity? Eur J Pharmacol 684: 19-26, 2012. 
XU TR, HE G, DOBSON K, ENGLAND K, RUMSBY M: Phosphorylation at Ser729 specifies a Golgi localisation for protein kinase C epsilon (PKCepsilon) in 3T3 fibroblasts. Cell Signal 19: 1986-1995, 2007.

YAN Y, ZHOU X, PAN Z, MA J, WASCHEK JA, DICICCO-BLOOM E: Pro- and anti-mitogenic actions of pituitary adenylate cyclase-activating polypeptide in developing cerebral cortex: potential mediation by developmental switch of PAC1 receptor mRNA isoforms. $J$ Neurosci 33: 3865-3878, 2013.

YE Y, PEREZ-POLO JR, AGUILAR D, BIRNBAUM Y: The potential effects of anti-diabetic medications on myocardial ischemia-reperfusion injury. Basic Res Cardiol 106: 925-952, 2011.

ZATTA AJ, KIN H, LEE G, WANG N, JIANG R, LUST R, REEVES JG, MYKYTENKO J, GUYTON RA, ZHAO ZQ, VINTEN-JOHANSEN J: Infarct-sparing effect of myocardial postconditioning is dependent on protein kinase C signalling. Cardiovasc Res 70: 315-324, 2006.

ZHAO ZQ: Postconditioning in reperfusion injury: a status report. Cardiovasc Drugs Ther 24: 265-279, 2010.

ZHAO ZQ, CORVERA JS, HALKOS ME, KERENDI F, WANG NP, GUYTON RA, VINTEN-JOHANSEN J: Inhibition of myocardial injury by ischemic postconditioning during reperfusion: comparison with ischemic preconditioning. Am J Physiol Heart Circ Physiol 285: H579-H588, 2003.

ZHOU JJ, BIAN JS, PEI JM, WU S, LI HY, WONG TM: Role of protein kinase C-epsilon in the development of kappa-opioid receptor tolerance to U50,488H in rat ventricular myocytes. Br J Pharmacol 135: 1675-1684, 2002.

ZHOU M, DIWU Z, PANCHUK-VOLOSHINA N, HAUGLAND RP: A stable nonfluorescent derivative of resorufin for the fluorometric determination of trace hydrogen peroxide: applications in detecting the activity of phagocyte NADPH oxidase and other oxidases. Anal Biochem 253: 162-168, 1997. 